\title{
Use of Social Robots in Mental Health and Well-Being Research: Systematic Review
}

Arielle AJ Scoglio, BA, MPH; Erin D Reilly, MEd, PhD; Jay A Gorman, PhD; Charles E Drebing, PhD

Social \& Community Reintegration Research Program, Edith Nourse Rogers Memorial Veterans Hospital, Bedford, MA, United States

Corresponding Author:

Arielle AJ Scoglio, BA, MPH

Social \& Community Reintegration Research Program

Edith Nourse Rogers Memorial Veterans Hospital

200 Springs Road, Mailstop 116A

Bedford, MA,

United States

Phone: 17816874527

Email: arielle.scoglio@va.gov

\section{Abstract}

Background: Technology-assisted clinical interventions are increasingly common in the health care field, often with the proposed aim to improve access to and cost-effectiveness of care. Current technology platforms delivering interventions are largely mobile apps and online websites, although efforts have been made to create more personalized and embodied technology experiences. To extend and improve on these platforms, the field of robotics has been increasingly included in conversations of how to deliver technology-assisted, interactive, and responsive mental health and psychological well-being interventions. Socially assistive robots (SARs) are robotic technology platforms with audio, visual, and movement capabilities that are being developed to interact with individuals socially while also assisting them with management of their physical and psychological well-being. However, little is known about the empirical evidence or utility of using SARs in mental health interventions.

Objective: The review synthesizes and describes the nascent empirical literature of SARs in mental health research and identifies strengths, weaknesses, and opportunities for improvement in future research and practice.

Methods: Searches in Medline, PsycINFO, PsycARTICLES, PubMed, and IEEE Xplore yielded 12 studies included in the final review after applying inclusion and exclusion criteria. Abstract and full-text reviews were conducted by two authors independently.

Results: This systematic review of the literature found 5 distinct SARs used in research to investigate the potential for this technology to address mental health and psychological well-being outcomes. Research on mental health applications of SARs focuses largely on elderly dementia patients and relies on usability pilot data with methodological limitations.

Conclusions: The current SARs research in mental health use is limited in generalizability, scope, and measurement of psychological outcomes. Opportunities for expansion of research in this area include diversifying populations studied, SARs used, clinical applications, measures used, and settings for those applications.

(J Med Internet Res 2019;21(7):e13322) doi: 10.2196/13322

\section{KEYWORDS}

social robotics; socially assistive robots; mental health; interventions

\section{Introduction}

\section{Overview}

There is a well-documented gap between individuals in need of support for mental health concerns and those who receive care [1-4]. To address the treatment disparity between individuals in need of psychiatric care and those who receive it, the field of mental health has expanded from offering exclusively in-office clinical care, including interventions such as psychotherapy, care management, and medication, to offering treatment in a wide array of settings and with varied interface platforms. The use of technology in providing at-home care options have identified both potential [5] and challenges [6].

One study found that technology-assisted support and treatments may be appealing to potential patients and health centers because telehealth delivery methods can improve access and are often cost effective [7]. There are multiple reasons why individuals may not be able to access needed care, including lack of 
available therapists [8], lack of transportation [9], stigma around engaging in mental health care [10], and financial barriers [11]. Mobile intervention options can also be used to extend in-person clinical treatments such as cognitive-behavioral therapy for insomnia or posttraumatic stress disorder treatments to the home $[12,13]$. Similarly, online interventions have the potential to reach patients who might otherwise not have access to mental health or other clinical care, as $82 \%$ of adults in the United States have access to either the internet at home or wireless mobile devices [14]. At-home technology platforms have attempted to meet the needs of such persons, to either replace or supplement in-person treatments [5,15].

Following initial program development, developers often purport that technology-supported behavioral interventions can be more easily implemented than in-person options, without the limitations of travel, local resources, training new practitioners to implement a treatment model, or monitoring treatment fidelity [16]. However, creating and implementing such systems can be difficult. For instance, real-world use of some mHealth tools by clinics and consumers remains low [17] even after the tools have been assessed for usability issues. At the same time, research has shown that mHealth tools may help clients self-manage their own treatment and goals across multiple diagnoses related to chronic physical and mental health challenges using apps, clinical portals, and texting interfaces $[18,19]$. Some research suggests that the utilization gap between developed technologies and their intended consumers may be related to engagement [20].

Although initial research appears promising, mHealth technology has documented limitations regarding treatment engagement [21,22]. Current mHealth technologies often rely on intervention strategies with minimal personalization and interactions, including mobile phone apps and one-way texting, which lack key factors of mental health interventions: real-time interactive engagement, simple user experiences, transdiagnostic capabilities within one platform, and personalized feedback [23]. Only recently has there been a push to develop and assess how socially interactive technologies, such as computer-animated virtual therapists, can be leveraged for mHealth interventions to support accountability, provide continuously tailored feedback, and form a social relationship to successfully impact client wellness [24]. Consequently, there is both a need for and room to improve the mHealth platforms used in mental health interventions to create a more client-centered and engaging experience.

\section{Social Robots and Well-Being}

To address engagement and motivational difficulties with mobile mental health interventions, researchers have begun to explore the possibility of using animated characters and social robots as personalized social companions to deliver or supplement behavioral interventions $[25,26]$. Socially assistive robots (SARs) are robotic technology platforms with audio, visual, and movement capabilities. Their purpose is to create friendly and effective interaction with a human user with the additional aim of giving assistance to the user and achieving measurable progress in quality of life, often related to motivation, rehabilitation, or learning [27]. SARs are embodied, taking up physical space in the world and not merely existing on a screen, and can use audio and/or closed captioning to converse socially with humans, depending on their design [28]. It is important to note that SARs are both platforms for interventions and also interventions in and of themselves; they can learn and engage socially with individuals while also presenting interventions to users similar to mobile apps (eg, skills training, health tracking). They can engage users across multiple sensory options, most often including sound, sight, and touch, which can create multiple modalities for the delivery of content or interactions, depending on user preferences or personal physical abilities [29]. Given their multiple abilities, SARs may potentially integrate traditional app- and telehealth-related supports with an interactive social companion, providing a more engaging and responsive platform for users.

Although research with SARs is still in its early stages, preliminary research has reported positive participant responses to SARs assisting in physical health interventions related to increasing exercise with the elderly [30], improved cardiac rehabilitation through self-reported usefulness of SARs to assist in completion of rehabilitation tasks [31], and improved medication management through medication reminders by an SAR [32]. These specific robots were created to serve as embedded reinforcers of tasks, health behaviors, and prosocial interactions and are used across a wide range of conditions. One study found that SARs may assist with weight management, motivation, and self-monitoring strategies, with engagement sustained beyond what has been found with the same treatment delivered passively online [26].

There is limited evidence that SARs can assist with mental health and well-being interventions in pediatric populations by providing comfort or coaching [33,34]. Additionally, a 2013 meta-analysis focusing on the psychological outcomes of robot-enhanced therapies suggests that social robots could be used as a complementary tool in therapy for specific populations, particularly with children [35]. The function of social robots in adult populations is different and should be studied separately; children and adolescents often respond differently to robots, and the focus should be on developmental and skill-based learning (eg, to support children's play [36] or assist adolescents with autism [37]). However, these platforms and their socially responsive capabilities can be modified to assist adults with their mental and behavioral health goals, given the dual nature of social robots to create personalized, affective relationships with users and assist in setting, tracking, and supporting users in meeting specific goals [38]. Unfortunately, little is known about the nature of social robots and their potential use in assisting in the psychological well-being of adult populations.

Social robots have been used in research with children, usually involving children with developmental disabilities [39]. However, the function of social robots is different in pediatric versus adult populations. Research with children focuses on robots as models of appropriate behavior or physical helpers with manual tasks [40]. There is more variability in the functionality of social robots in research with adults, thus we restricted our search to adult populations. 
There is room for expansion in the use of SARs in mental health research with adults and how the research into robots and mental health has developed in recent years given the fast-paced nature of robotics. Reviewing the existing empirical literature on the use of social robots for mental health interventions is essential to determine the current state of the research and make suggestions regarding future areas for investigation. This systematic review of the literature attempts to synthesize studies using social robots to affect mental health and psychological well-being outcomes, identify the current strengths and weaknesses in the research, and suggest opportunities for growth and exploration.

\section{Methods}

This study is a systematic synthesis of the literature from the past 10 years that examines the use of social robots in mental health and psychological well-being. The fields of robotics and artificial intelligence are rapidly changing and this review is meant to reflect the current research in this area. We sought to answer the question: How have social robots been used to enhance mental health services for adults? A search was conducted on June 20, 2018, in the databases Medline, PsycINFO, PsycARTICLES, PubMed, and IEEE Xplore. We used several search term combinations to search titles, abstracts, keywords, and text in articles: social robot* + mental health, social robot* + counseling, social robot* + therapy, social robot* + psychotherapy, socially assistive robot $^{*}+$ mental health, socially assistive robot* + counseling, socially assistive robot* + therapy, socially assistive robot* + psychotherapy. Search terms were developed in consultation with coauthors and a research librarian. In our search, we excluded studies published in languages other than English, studies published prior to 2008, and studies that focused on pediatric populations. This search yielded 48 articles in total for abstract review after removing duplicates $(n=9)$. Exact search strings for each database are included in Multimedia Appendix 1.

The authors used Covidence.org to organize the review and conduct blinded abstract and full-text reviews. This review is not formally registered. Two authors independently reviewed all abstracts and met to come to consensus on the inclusion or exclusion of articles in conflict. The inclusion criteria were that the article was an empirical study involving data collected on the direct interactions between a human participant (aged 18 years or older) and a social robot (an embodied robotic platform meant to form an assistive or affective connection with users) and that the authors explicitly stated their study focused on a mental health treatment population (eg, psychiatric patients) or used a mental health-focused intervention (eg, motivational interviewing). Included studies had to report on one or more mental health or psychological well-being outcomes with data collected to measure the robot's possible relationship with the mood, psychological welfare, or comfort of users. Although our search process did not include the term psychological well-being, it became clear in our review process that articles that explicitly aimed to examine mental health actually measured aspects of well-being rather than specific mental health constructs. Thus, we expanded our inclusion criteria to include measurement of a psychological well-being outcome. Twenty-four articles were excluded in the abstract review process, detailed in Figure 1. There was a discrepancy on rating abstracts with 2 articles that was resolved through consensus agreement, indicating good interrater reliability. This left 24 articles for full-text review. The same two authors independently reviewed all 24 full-text articles and met to resolve any conflicts by consensus agreement. Twelve articles were excluded in the full-text review phase because they did not use an empirical design (eg, it was a theoretical or commentary paper) or the focus of the study was not on mental health or well-being (eg, mental health was not a primary outcome). Twelve studies remained for inclusion in our final review.

Data were extracted from the 12 articles included in the final review. Specifically, detailed information about the sample size and characteristics of the population, study design, mental health or well-being outcome and measurement, robot used, intervention implemented, study findings, and possible biases were all recorded. Details about definitions of mental health or well-being outcome and purpose of the intervention were also identified. Studies were assessed for methodological quality, but quality assessments were not used to exclude any studies. Instead, quality assessments served to identify consistent weaknesses across studies. Contact with individual study authors was ultimately not deemed necessary to extract needed information from the included studies. 
Figure 1. Preferred Reporting of Systematic Reviews Search and Review diagram.

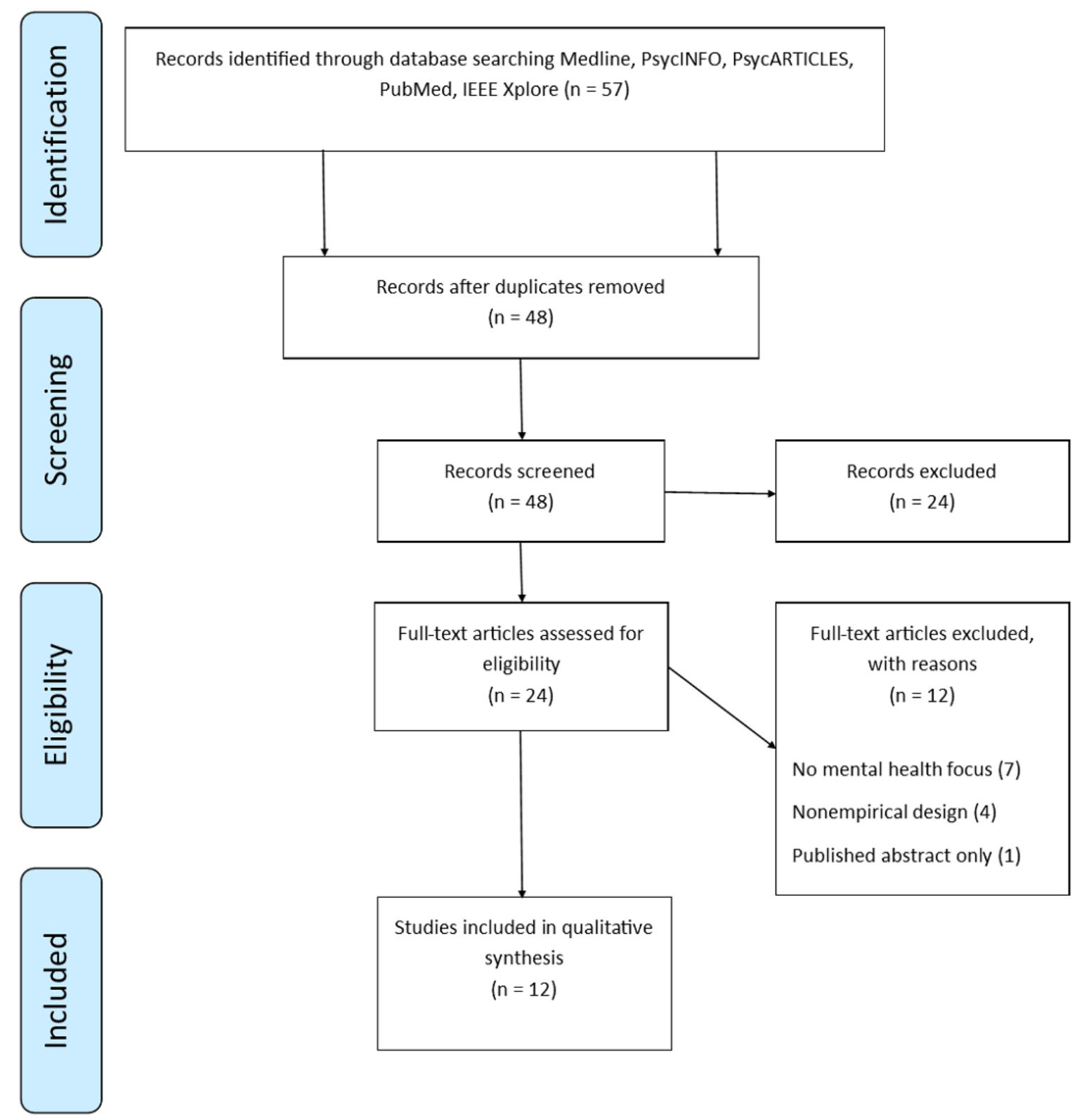

\section{Results}

\section{Summary}

The 12 studies included in our review used 5 different social robots (Paro, NAO, CRECA, Betty, and Haptic Creature) constituting 3 major areas of robotic applications for mental health developed from our review: comfort/companionship, stress reduction, and motivation. The studies were published between 2010-2018 in a variety of peer-reviewed journals; 4 studies were published conference papers. Sample sizes for the studies ranged from 2 to $248 ; 7$ of the 12 studies were conducted in elderly populations in nursing home settings, 2 were conducted with college students, 2 with hospital staff, and 1 with women aged 19 to 45 years recruited from the community. A minority of studies $(n=3)$ focused on participants who were aged 45 years or less. Three studies were not conducted with a clinical mental health sample but from participants recruited from the community or from local colleges. These studies were included in the review because they measured mental health or well-being outcomes such as self-reported anxiety or stress reduction. Table 1 describes the studies, samples, interventions, and main findings with respect to the effects of social robots on psychological outcomes collected in our review. 
Table 1. Main evidence from systematic review.

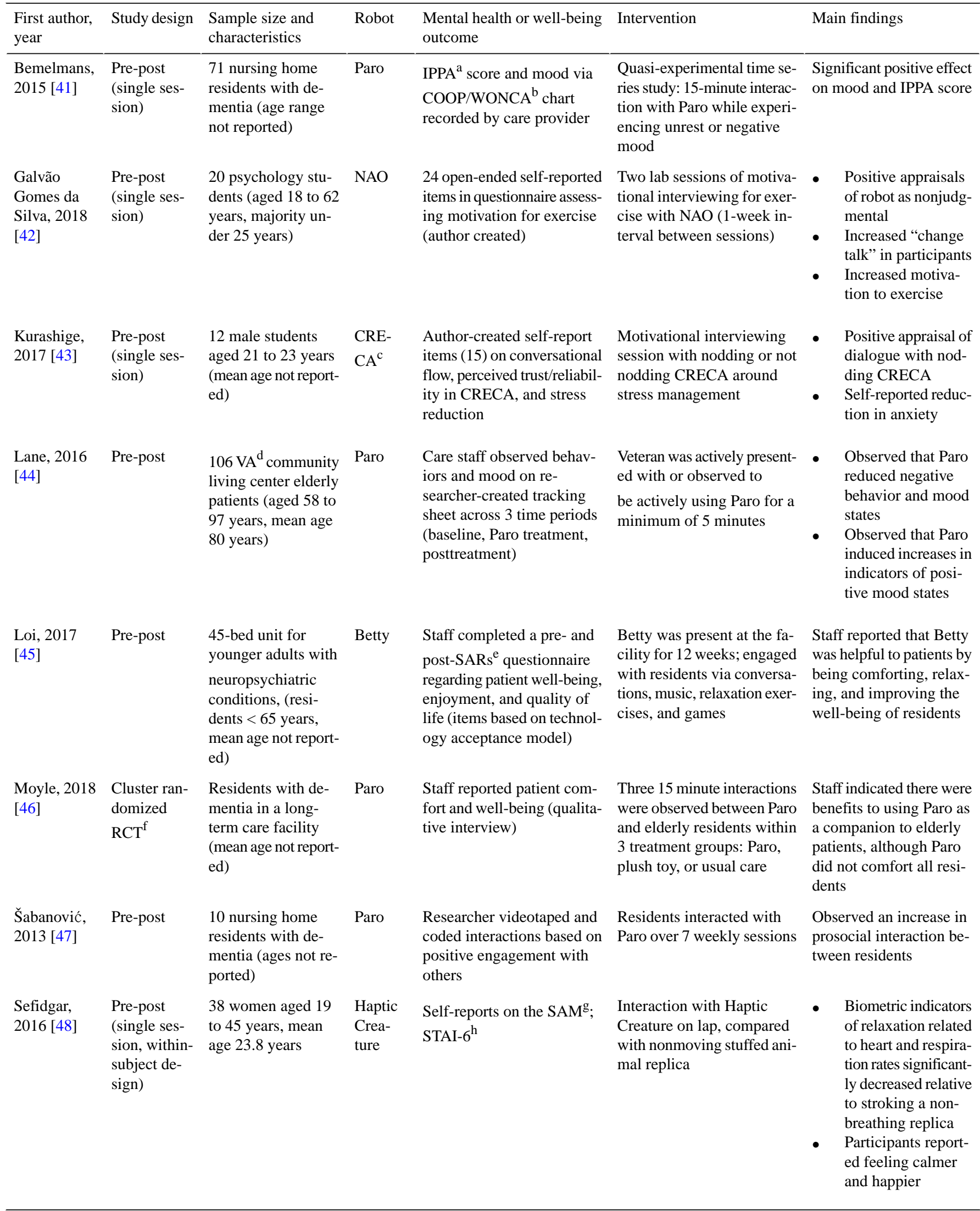




\begin{tabular}{|c|c|c|c|c|c|c|}
\hline $\begin{array}{l}\text { First author, } \\
\text { year }\end{array}$ & Study design & $\begin{array}{l}\text { Sample size and } \\
\text { characteristics }\end{array}$ & Robot & $\begin{array}{l}\text { Mental health or well-being } \\
\text { outcome }\end{array}$ & Intervention & Main findings \\
\hline $\begin{array}{l}\text { Valentí Sol- } \\
\text { er, 2015 [49] }\end{array}$ & Pre-post & $\begin{array}{l}211 \text { nursing home } \\
\text { patients with demen- } \\
\text { tia, } 37 \text { at day care } \\
\text { facility (total } n=248 \text {; } \\
\text { age range } 58 \text { to } 100 \\
\text { years, mean age } 84.7 \\
\text { years }\end{array}$ & $\begin{array}{l}\text { Paro, } \\
\text { NAO }\end{array}$ & $\begin{array}{l}\text { Staff reported on the Apathy } \\
\text { Inventory and QUALID } \\
\text { scale }\end{array}$ & $\begin{array}{l}\text { Comparing interactions with } \\
\text { Paro, NAO, and live dog } \\
\text { over } 3 \text { months }\end{array}$ & $\begin{array}{l}\text { - Apathy and irritabil- } \\
\text { ity improved for } \\
\text { NAO and Paro } \\
\text { groups } \\
\text { Quality of life im- } \\
\text { proved for Paro } \\
\text { group }\end{array}$ \\
\hline $\begin{array}{l}\text { Wada, } 2010 \\
{[50]}\end{array}$ & Pre-post & $\begin{array}{l}2 \text { elderly individuals } \\
\text { and } 1 \text { caregiver, age } \\
\text { not reported }\end{array}$ & Paro & $\begin{array}{l}\text { Researcher observed emo- } \\
\text { tional responses and behav- } \\
\text { iors (ie, smiling) }\end{array}$ & $\begin{array}{l}\text { Caregivers engaged in a } \\
\text { manual-assisted } 30 \text {-minute } \\
\text { interaction between resi- } \\
\text { dents and Paro ( } 4 \text { sessions) }\end{array}$ & $\begin{array}{l}\text { Observed-recorded in- } \\
\text { crease in positive behav- } \\
\text { iors in } 1 \text { participant } \\
\text { (smiling, laughing), no } \\
\text { significant change in oth- } \\
\text { er participant }\end{array}$ \\
\hline $\begin{array}{l}\text { Wada, } 2012 \\
{[51]}\end{array}$ & Pre-post & $\begin{array}{l}12 \text { elderly partici- } \\
\text { pants (mean age } \\
86.8 \text { years) and } 9 \\
\text { caregivers (mean } \\
\text { age } 28.1 \text { years) }\end{array}$ & Paro & $\begin{array}{l}\text { Observation sheet recording } \\
\text { participant behaviors and } \\
\text { emotional reactions (re- } \\
\text { searcher-recorded) }\end{array}$ & $\begin{array}{l}\text { Manual-assisted interaction } \\
\text { with Paro; observed before } \\
\text { caregiver used manual and } \\
\text { after caregiver used manual }\end{array}$ & $\begin{array}{l}\text { The manualized Paro in- } \\
\text { teraction increased con- } \\
\text { tentment and positive so- } \\
\text { cial interactions }\end{array}$ \\
\hline $\begin{array}{l}\text { Wada, } 2014 \\
\text { [52] }\end{array}$ & Pre-post & $\begin{array}{l}64 \text { elderly individu- } \\
\text { als in } 7 \text { elder-care } \\
\text { facilities (mean age } \\
86.5 \text { years) }\end{array}$ & Paro & $\begin{array}{l}\text { Observation sheet recording } \\
\text { perceived participant behav- } \\
\text { iors and mood (anxiety, de- } \\
\text { pression, aggression) }\end{array}$ & $\begin{array}{l}\text { Manual-assisted interaction } \\
\text { with Paro over } 5 \text { months }\end{array}$ & $\begin{array}{l}\text { Following Paro interac- } \\
\text { tions, caregivers ob- } \\
\text { served decreases in per- } \\
\text { ceived anxiety, depres- } \\
\text { sion, or aggression in } 25 \\
\text { residents }(39 \%)\end{array}$ \\
\hline
\end{tabular}

aPPA: Individually Prioritized Problems Assessment.

${ }^{\mathrm{b}}$ COOP/WONCA: Primary Care Cooperative Information Project/World Organization of Colleges, Academies, and Academic Associations of General Practitioners/Family Physicians.

${ }^{\mathrm{c} C R E C A:}$ Contextual Respectful Counseling Agent.

${ }^{\mathrm{d}}$ VA: US Department of Veterans Affairs.

${ }^{\text {e}} \mathrm{SAR}$ : socially assistive robot.

${ }^{\mathrm{f} C T}$ : randomized controlled trial.

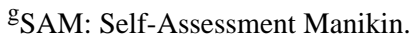

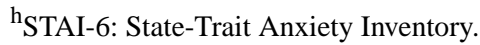

${ }^{\mathrm{i}}$ QUALID: Quality of Life in Late Stage Dementia.

\section{Robotic Devices}

A majority of studies $(n=8)$ used Paro, a robot that resembles a baby harp seal, with 2 studies using NAO, and 1 study using CRECA (Contextual Respectful Counseling Agent), Haptic Creature, and Betty. In Figure 2 and Table 2, pictorial and text descriptions of the 5 social robots are provided. Overall, the appearance of the robots used matched their purpose, with Paro and the Haptic Creature resembling animals, as the researchers aimed to use audio, visual, and tactile sensors to mimic animal-assisted therapy. The humanoid SARs (CRECA, Betty, and NAO) had audio, visual, and tactile sensors as well but also used additional sensors to communicate verbally with users to provide interactions related to relaxation or mental health treatment (ie, counseling, motivational interviewing). Although all the robots were capable of limited movement, only NAO was able to walk and assume a standing position if needed. The weight of the robots varied greatly, with the heaviest weighing $14 \mathrm{lbs}$ (Betty) and the lightest weighing $6 \mathrm{lbs}$ (Paro; information on height/weight of CRECA not available). 
Figure 2. Social robots used in reviewed articles: (a) Paro, AIST [41]; (b) Haptic Creature [48], photo by Martin Dee; (c) NAO, Aldebaran Robotics; (d) Betty [45]; and (e) CRECA [43].
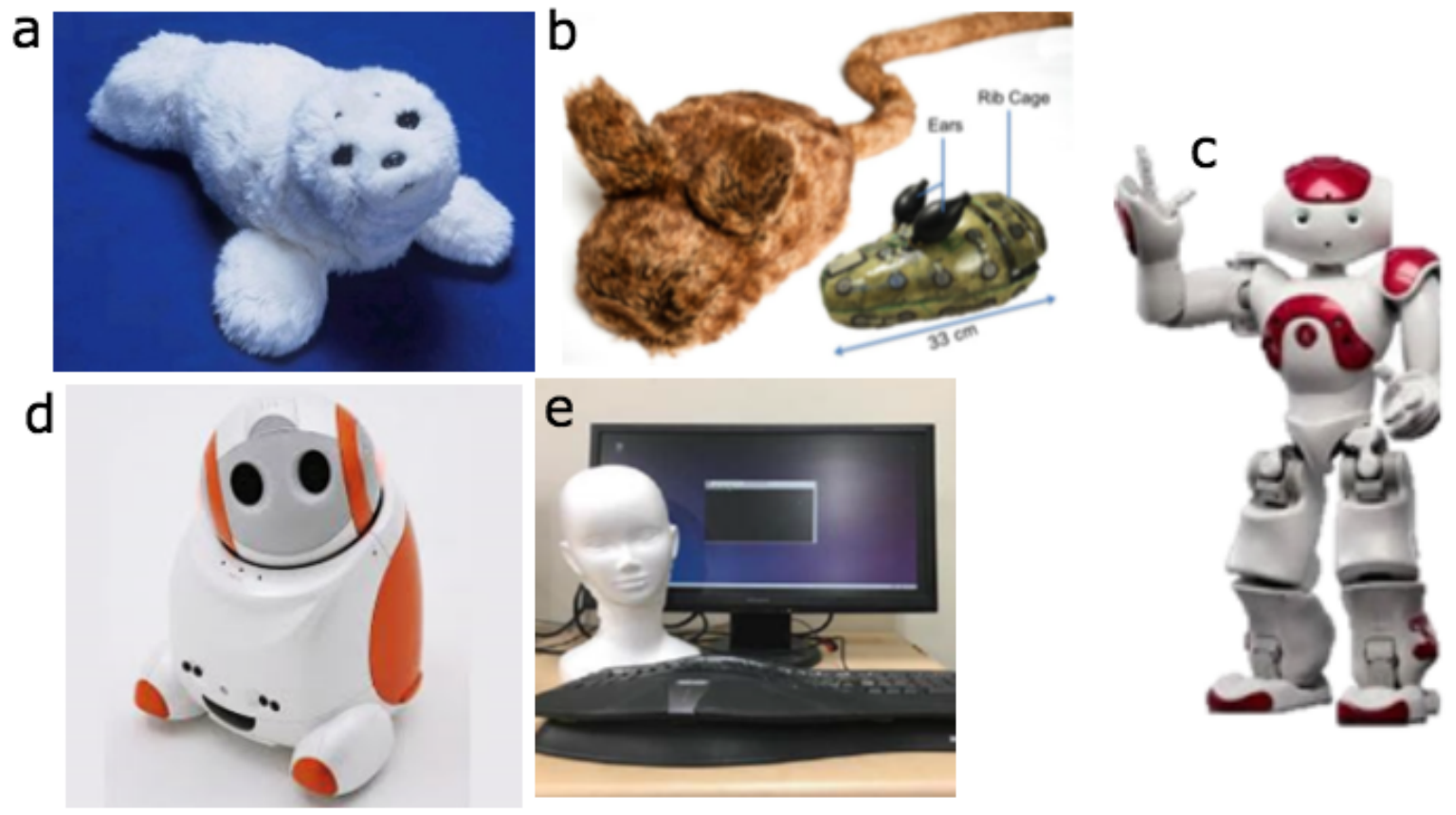
Table 2. Description of social robots used in reviewed articles.

\begin{tabular}{|c|c|c|c|c|}
\hline Robot & Physical appearance and specs & Sensors & User interactivity & Purpose \\
\hline Paro & $\begin{array}{l}\text { Paro is a robotic harp seal, } \\
\text { weighing } 6 \text { lbs and } 22.4 \text { inches } \\
\text { long. Paro can be recharged } \\
\text { through its "pacifier" battery } \\
\text { charger. Its fur is removable, } \\
\text { washable, fluffy, and antibacte- } \\
\text { rial. The US Food and Drug } \\
\text { Administration has classified }\end{array}$ & $\begin{array}{l}\text { Has five kinds of sensors: tac- } \\
\text { tile, light, audition, tempera- } \\
\text { ture, and posture sensors, with } \\
\text { which it can perceive people } \\
\text { and its environment. }\end{array}$ & $\begin{array}{l}\text { He can sense when being } \\
\text { touched by its tactile sensor, or } \\
\text { when being held by a posture } \\
\text { sensor. Can also recognize the } \\
\text { direction of voice and words } \\
\text { such as its name, greetings, and } \\
\text { praise with its audio sensor. His } \\
\text { voice imitates a harp seal. }\end{array}$ & $\begin{array}{l}\text { Paro is meant to provide similar } \\
\text { comfort as animal therapy for } \\
\text { patients in facilities where live } \\
\text { animals may present treatment } \\
\text { or logistical difficulties. Paro } \\
\text { may be used for comfort, com- } \\
\text { panionship, or stress reduction. }\end{array}$ \\
\hline
\end{tabular}

Betty Betty is an individualized, socially-assistive robot, with the technological name Partner Personal Robot PaPeRo. Betty is 15.35 inches tall and weighs about $14 \mathrm{lbs}$. Betty is programmable by users external to the company.

NAO NAO is brightly colored with large eyes and humanoid appearance. NAO stands at 22.8 inches tall and weighs $12.1 \mathrm{lbs}$. Its default walking speed is 0.2 $\mathrm{mph}$. The robot is fully programmable.

Haptic Creature The Haptic Creature is a comfort robot and was designed based on human-animal interaction models. It is characterized as an expressive animatronic lap-pet (size of a large cat). It is 12.9 inches long and weighs $5.5 \mathrm{lbs}$. The platform utilizes custom programming that may be available to external programmers upon request.

CRECA CRECA stands for "Context Respectful Counseling Agent" and works in conjunction with an on-screen counseling agent avatar. The platform utilizes custom programming that may be available to external programmers upon request
Betty has audio, touch, movement, and visual sensors; specifically, it is equipped with a camera, microphone, a touch pad, and speakers.

It has multiple sensors for touch, sound, speech, and visual recognition. NAO is also capable of movement, with both fall and fall recovery capabilities.

Includes a 30-item touch dictionary developed from social psychology and human-animal interaction literature. It perceives movement and touch, responding with ear stiffness, modulated breathing, and vibrotactile purring.

This robot is connected to a computer and microphone to perform speech functions using natural language processing. It can also perform nodding movements.
Voice recognition is the primary modality for interacting with Betty. The robot can also make human-like gestures, has voice recognition capabilities, is mobile, and can be programmed with a person's preferences (eg, books, games, or music)

$\mathrm{NAO}$ interacts with users via an audio system, often with accompanying movements and lights. It has speech recognition and dialogue with NAO is available in 20 languages.

Users interact with the Haptic Creature solely through touch, with the robot responding with movement and visual cues to mimic relaxed breathing.
Betty may be used for motivation, entertainment, or companionship. The robot is meant to provide human-like interactions and reciprocal engagement, while also providing a calming effect for users.

It has been used in research with children who have developmental disorders or disabilities. NAO is also used for motivation or companionship

Through touch, it promotes emotional interaction with the user with the aims to reduce anxiety similar to animal assisted therapy. It can also be used for comfort or stress reduction.
It can converse with the users, respond to client verbalizations with prompts for continued discussion, and nod its head to validate the user's responses.
CRECA primarily serves as an educational or motivational robot that can mimic the verbal and non-verbal interactions between counselors and clients

\section{Study Interventions}

The reviewed studies had 2 types of interventions and varied in robotic-interaction frequency. Four studies conducted a single-time lab research session to assess their SARs [41-43,48], while the majority $(n=8)$ embedded their SARS within a facility over a specified period of time to evaluate the impact of their SARs on residents. None of the studies employed a robot within the personal home of a participant. Although inclusion criteria were meant to capture SAR research with a mental health focus and on persons with identified mental health issues, no studies were conducted specifically with persons reporting psychological diagnoses.
In the reviewed studies, the SAR was used as the intervention, and participants were assessed to see if interacting with the robot resulted in changes in well-being or mental health. In addition, although all of the studies used at least one social robot as the main platform for a well-being or mental health intervention, one [49] used two robots in order to compare either a live animal, Paro, or NAO as the mode of delivering comfort to nursing home residents with dementia. In addition, 3 studies $[43,46,48]$ used less responsive comparisons as controls for their SARS, including a plush animal comparison $(n=2)$ or a nonnodding CRECA $(n=1)$. A minority of studies $(n=2)$ used an SAR as a platform to conduct motivational interviewing sessions with social robots, one focused on motivation to exercise using NAO and the other focused on stress reduction 
using CRECA $[43,48]$. The remaining 10 research studies focused on the social robot as a means of comforting, increasing positive emotions, or providing companionship to participants, with 9 of these using the robots within the context of elderly or long-term care settings.

\section{Study Design and Measurement}

Our review revealed that 6 of the studies used clinical care staff to observe and measure outcomes related to mood and mood-related behavioral changes, 3 used self-report data $[42,43,48]$, and 3 had researchers use tracking sheets $[44,46,50]$ to report on mood and mental health outcomes. These methods may be an artifact of the populations studied, due to the majority of studies involving persons with cognitive issues who would make self-report challenging. In addition, only 4 studies [41,46,48,49] used nonresearch-created questionnaires, using previously validated measurements such as the Apathy Inventory and Quality of Life in Late Stage Dementia scale. Although one study [46] used an RCT (randomized controlled trial) study design, most of the studies $(n=11)$ used a pre-post design, measuring changes in psychological well-being or intervention impact before and after interacting with a SAR.

\section{Mental Health Outcomes}

Overall, results regarding the impact of social robot-delivered mental health interventions and interactions ranged from generally positive to mixed. The majority of studies focused on symptom reduction related to mood and positive quality of life changes after robot interactions. The majority $(n=11)$ reported positive increases in mood, comfort, or stress reduction following the social robot interventions, although 2 [46,50] showed mixed results on whether Paro comforted elder-care residents. For the 7 studies that focused on elderly and dementia populations, outcomes included observed aggression, contentment, anxiety, and depression [41,44,45,49-52]. However, nearly all studies had a main goal of assessing feasibility or usability of the social robot in a given population. Since mental health outcomes were secondary and these studies were pilot studies, psychometrically validated measures were seldom used and instead measures were frequently created for the particular study.

Two studies reported on functional outcomes related to quality of life. These studies focused specifically on physical health and well-being, with one reporting a generally positive impact on exercise [42] and one reporting a reduction in physical indicators of stress and an increase in self-reported mood after interaction with a social robot [41]. Finally, 2 studies assessed the ways in which social robots facilitate positive social interactions, with one reporting increased social interaction among participants in a nursing home and their caregivers following an interaction with Paro [51] and the other noting that social interactions among residents in a nursing home increased after Paro was integrated into the facility [47].

\section{Discussion}

\section{Principal Findings}

Overall, our review revealed the nascent nature of mental health research with social robots. Although there is a rising interest in using social robots in psychological interventions, there is still a very modest research base examining this application. Our 12 reviewed studies included the use of 5 distinct social robots to influence various mental health or well-being outcomes. The majority focused on providing comfort and companionship to study participants (Paro, Haptic Creature). A minority of studies used SARs to implement a specific intervention (eg, motivational interviewing with NAO and nodding CRECA). The impact of social robot-delivered mental health interventions and interactions ranged from generally positive to mixed, with some studies finding positive changes in mood and quality of life after robot interactions.

This review suggests that existing studies of the potential impact of SARs on psychological well-being are limited in generalizability, scope, and measurement. Specifically, nearly all of the studies conducted in this area have occurred in elderly care facilities or laboratory settings, with a bimodal distribution of participants ranging from quite young (under 24) to elderly populations within nursing home facilities (often over 65 years). Our findings are consistent with a previous review of SAR use in care of the elderly [35]), which found studies in this area to be methodologically limited, so much so that even optimistic findings required additional replication prior to making clear conclusions about SAR effectiveness. This also relates to our finding that the majority of reviewed studies used clinical care or researcher-reported outcomes. Specifically, since multiple studies were conducted with elderly samples suffering from dementia or neuropsychiatric conditions, observational data may have been considered most feasible and more valid than self-report data. Similarly, surveying caretakers of impaired elderly persons may have been more feasible than surveying the patients themselves. The lack of validated scales used in the studies underscores the nascent state of this field and the need for further and more structured research.

Social robot-delivered interventions may constitute a promising treatment for chronic conditions and health management needs in elderly populations based on the findings of studies included in this review. In particular, the available data indicate that Paro may be a useful tool for increasing socialization and decreasing aggression in dementia populations. However, there is insufficient evidence that this finding can be generalized to other populations or even to nursing home residents without dementia. In addition, some studies identified were conference paper proceedings, which highlights a limitation of the research. Conference papers are not necessarily peer reviewed and may indicate a higher risk of bias.

\section{Limitations}

Generalizability of these findings is also limited by the study characteristics. Many of the studies had very small sample sizes, which also limits the generalizability of findings. Moreover, included studies frequently had very brief interventions with simple pre-post study designs, which might make it difficult to assess differences in pre and post data and preclude conclusions about the efficacy of the interventions. We did not include specific mental health diagnoses in our searches, and therefore some studies using SARs to target very specific diagnoses, rather than mental health more generally, may have been 
excluded. In addition, we did not include papers that focused only on the development of a particular SAR because we only included studies that had participants. There is also a lack of definitional clarity in the concept of social robots in general, and this may lead to different conceptualizations of SARs in the literature.

There is a clear need for greater testing and programming of robots to assist with patient care within the home. Although many of the research studies reported a future aim of using social robots within the home for mental health support and interventions, no study had currently begun this level of at-home technology testing. Without such testing, it is unclear whether an at-home mental health companion, coach, or motivator would have a strong positive effect on the quality of life of patients managing their depression, anxiety, or other psychiatric conditions where health happens most-in the home. Choosing the appropriate SAR to use for future research should entail a review of not only this research but also the robot characteristics necessary for the user. For instance, many of the robots reviewed weighed more than $10 \mathrm{lbs}$, which can be contraindicated with certain populations should they need to lift the SAR. Such considerations are imperative in order to align an intervention's purpose, user, and chosen robotic platform.

Methodologically, there is room for improving and extending the current research base of social robots in mental health interventions. The results of this review show that nearly all studies in this area are preliminary or pilot studies, and few include validated measures of mental health outcomes. Often, the primary aim of such research is usability, feasibility, and acceptability of the social robots with mental health measures secondary to this main goal. Mental health outcomes were often vaguely defined as the observed reduction of anxiety or negative mood symptoms. Expanded use of self-report questionnaires or clinician-administered measures with psychometric validation is indicated. In addition, outcomes should be aligned with what patients might care about in treatment outcomes, which may include an increase in functional abilities, social interactions, or self-reported quality of life. Nearly all of the studies reviewed used single-session robot interactions that may make tracking changes in mental health difficult. As previously stated, many studies included participants with cognitive difficulties, which might make self-report assessments difficult or impossible, hence their use of observed mental health outcomes. However, if the purpose of social robot-delivered treatments is to capitalize on the functionality of such robots-neutral, asynchronous, always available, and capable of personalized tracking and feedback - such testing and adequate measurement is essential to the creation of patient-centered social robots. Because of the heterogeneity in how outcomes were reported, we could not perform a meta-analysis or draw conclusions about possible biases at work across studies.

\section{Practical Implications and Future Research}

After reviewing the existing research on social robots and mental health, it is clear that there are ample opportunities to test and measure the ways social robots could be useful adjuncts to mental health treatments for various adult populations. Current research has used mental health outcomes as a secondary focus, and future research should explore the potential benefits of SARs in specific clinical populations with difficulty accessing care. Examples of such populations might include veterans living with chronic pain in rural areas, individuals with mental health needs who cannot make appointments during regular business hours, individuals with transportation issues, or individuals who feel stigmatized in traditional mental health care settings. Exploration of motivational, companionship, and social facilitation functions of SARs were assessed in a minority of studies. In Table 3, we highlight further recommendations and areas of consideration for future research into the mental health and clinical applications of social robots.

Table 3. Considerations and recommendations for future research.

\begin{tabular}{ll}
\hline Research considerations & Recommendations \\
\hline Internal validity & - Improve upon and expand methods beyond pilot studies \\
& $\begin{array}{l}\text { - } \quad \text { Use validated mental health outcome measures when advancing beyond pilot feasibility studies } \\
\text { - Account for potential mediators between socially assistive robot interactions and mental health outcomes, } \\
\text { such as usability or technology issues }\end{array}$
\end{tabular}

External validity/generalizability - Expand beyond dementia and developmentally disordered populations to include a range of ages and diagnoses (with special attention to those who may not currently have access to needed care)

- Explore use of socially assistive robots across different settings, from medical facilities to at-home robots

Inclusion of theory

Dissemination and translation

Cultural concerns
- Use existing literature on human-robot interactions to account for study aims and interventions design decisions

- Embed psychological theory into future research — such as object relations- to explore individual mental health outcomes and reactions and perceived efficacy of socially assistive robots

- Expand future research to robots that can engage in more human-like social interaction

- Consider close, multidisciplinary collaborations (eg, between clinicians, researchers, and robotics programmers) to allow for iterative and responsive intervention development

- Investigate the impact of sociocultural beliefs and differences related to technology comfort, linguistic challenges, and interest in socially assistive robots for mental health

- Focus on specific mental health populations that might be uniquely suited to benefit from socially assistive robots 


\section{Conclusions}

Our review sought to examine how social robots have been used to influence mental health in general, and a possible limitation of our review is that we chose not to include specific mental health terms (eg, depression) in our search process. In addition, since our search, which focused on mental health, yielded studies that mostly assessed aspects of well-being, it is possible that including multiple more specific mental health terms might have yielded different results.

Overall, better integrating and expanding on the mental health implications of social robots will clearly complement the ongoing drive in the field of psychology to better assist clients at home with supportive exercises, goal tracking, and an asynchronous care option. Although our review revealed that the use of SARs in mental health research is not yet widespread, new robots and programming are constantly changing, adapting, and expanding. The use of SARs in mental health research and mental health interventions is nascent and has thus far been restricted to specific populations with limited measurement and scope. There is an abundance of opportunity in this area for growth, expansion, and exploration to triangulate SARs usability and efficacy data as the next step in advancing this field.

\section{Acknowledgments}

This material is the result of work supported with resources and the use of facilities at the Edith Nourse Rogers Memorial Veterans Hospital. The findings and interpretations of the data expressed in the article are the sole responsibilities of the authors and do not necessarily represent the views of the Department of Veterans Affairs.

\section{Conflicts of Interest}

None declared.

\section{Multimedia Appendix 1}

Search strings.

[DOCX File, 14KB-Multimedia Appendix 1]

\section{References}

1. Lawrence D, Kisely S. Inequalities in healthcare provision for people with severe mental illness. J Psychopharmacol 2010 Nov;24(4 Suppl):61-68 [ [FREE Full text] [doi: 10.1177/1359786810382058] [Medline: 20923921]

2. Saxena S, Thornicroft G, Knapp M, Whiteford H. Resources for mental health: scarcity, inequity, and inefficiency. Lancet 2007 Sep;370(9590):878-889. [doi: 10.1016/s0140-6736(07)61239-2]

3. Goddard M, Smith P. Equity of access to health care services: theory and evidence from the UK. Soc Sci Med 2001 Nov;53(9):1149-1162. [doi: $10.1016 / \mathrm{s} 0277-9536(00) 00415-9$ ]

4. West A, Weeks WB. Physical and mental health and access to care among nonmetropolitan veterans health administration patients younger than 65 years. J Rural Health 2006 Jan;22(1):9-16. [doi: 10.1111/j.1748-0361.2006.00014.x]

5. Dahl T, Boulos M. Robots in health and social care: a complementary technology to home care and telehealthcare? Robotics 2013 Dec 30;3(1):1-21. [doi: 10.3390/robotics3010001]

6. Peeters JM, Wiegers TA, Friele RD. How technology in care at home affects patient self-care and self-management: a scoping review. Int J Environ Res Public Health 2013 Oct 29;10(11):5541-5564 [FREE Full text] [doi: 10.3390/ijerph10115541] [Medline: 24173139]

7. Heapy AA, Higgins DM, Goulet JL, LaChappelle KM, Driscoll MA, Czlapinski RA, et al. Interactive voice response-based self-management for chronic back pain: the COPES noninferiority randomized trial. JAMA Intern Med 2017 Dec 01;177(6):765-773 [FREE Full text] [doi: 10.1001/jamainternmed.2017.0223] [Medline: 28384682]

8. Comer JS. Introduction to the special series: applying new technologies to extend the scope and accessibility of mental health care. Cogn Behav Pract 2015 Aug;22(3):253-257. [doi: 10.1016/j.cbpra.2015.04.002]

9. Wang J. Perceived barriers to mental health service use among individuals with mental disorders in the Canadian general population. Med Care 2006 Feb;44(2):192-195. [Medline: 16434920]

10. Levin M, Stocke K, Pierce B, Levin C. Do college students use online self-help? A survey of intentions and use of mental health resources. J Coll Stu Psychother 2017 Oct 09;32(3):181-198. [doi: 10.1080/87568225.2017.1366283]

11. Andrade L, Alonso J, Mneimneh Z, Wells J, Al-Hamzawi A, Borges G, et al. Barriers to mental health treatment: results from the WHO World Mental Health surveys. Psychological medicine 2014;44(6):1303-1317. [Medline: 23931656]

12. Kuhn E, Weiss B, Taylor K, Hoffman JE, Ramsey KM, Manber R, et al. CBT-I Coach: a description and clinician perceptions of a mobile app for cognitive behavioral therapy for insomnia. J Clin Sleep Med 2016 Apr 15;12(4):597-606 [FREE Full text] [doi: 10.5664/jesm.5700] [Medline: 26888586]

13. Kuhn E, Greene C, Hoffman J, Nguyen T, Wald L, Schmidt J, et al. Preliminary evaluation of PTSD Coach, a smartphone app for post-traumatic stress symptoms. Mil Med 2014 Jan;179(1):12-18. [doi: 10.7205/MILMED-D-13-00271] [Medline: $\underline{24402979]}$ 
14. Ryan C, Lewis J. US Department of Commerce, Economics and Statistics Administration, US Census Bureau. 2015. Computer and internet use in the United States URL: https://www.census.gov/content/dam/Census/library/publications/ 2017/acs/acs-37.pdf [accessed 2019-06-24]

15. Cahill S, Macijauskiene J, Nygård A, Faulkner J, Hagen I. Technology in dementia care. Technol Disabil 2007;19(2):55-60 [FREE Full text]

16. Ebert DD, Cuijpers P, Muñoz RF, Baumeister H. Prevention of mental health disorders using internet- and mobile-based interventions: a narrative review and recommendations for future research. Front Psychiatry 2017 Aug;8:116 [FREE Full text] [doi: 10.3389/fpsyt.2017.00116] [Medline: 28848454]

17. Torous J, Nicholas J, Larsen M, Firth J, Christensen H. Clinical review of user engagement with mental health smartphone apps: evidence, theory and improvements. Evid Based Ment Health 2018 Aug;21(3):116-119. [doi: 10.1136/eb-2018-102891] [Medline: 29871870]

18. Parmanto B, Pramana G, Yu DX, Fairman AD, Dicianno BE, McCue MP. iMHere: a novel mhealth system for supporting self-care in management of complex and chronic conditions. JMIR Mhealth Uhealth 2013 Jul 11;1(2):e10 [FREE Full text] [doi: 10.2196/mhealth.2391] [Medline: 25100682]

19. Berrouiguet S, Baca-García E, Brandt S, Walter M, Courtet P. Fundamentals for future mobile-health (mHealth): a systematic review of mobile phone and Web-based text messaging in mental health. J Med Internet Res 2016 Dec 10;18(6):e135 [FREE Full text] [doi: 10.2196/jmir.5066] [Medline: 27287668]

20. Peters D, Calvo RA, Ryan RM. Designing for motivation, engagement and wellbeing in digital experience. Front Psychol 2018 May;9:797. [doi: 10.3389/fpsyg.2018.00797] [Medline: 29892246]

21. Perski O, Blandford A, West R, Michie S. Conceptualising engagement with digital behaviour change interventions: a systematic review using principles from critical interpretive synthesis. Transl Behav Med 2017 Dec;7(2):254-267 [FREE Full text] [doi: 10.1007/s13142-016-0453-1] [Medline: 27966189]

22. Short C, Rebar A, Plotnikoff R, Vandelanotte C. Designing engaging online behaviour change interventions: a proposed model of user engagement. Health Psychol Rev 2015;17(1):32-33 [FREE Full text]

23. Chandrashekar P. Do mental health mobile apps work: evidence and recommendations for designing high-efficacy mental health mobile apps. mHealth 2018 Mar;4:6. [doi: 10.21037/mhealth.2018.03.02]

24. Santarossa S, Kane D, Senn CY, Woodruff SJ. Exploring the role of in-person components for online health behavior change interventions: can a digital person-to-person component suffice? J Med Internet Res 2018 Apr 11;20(4):e144 [FREE Full text] [doi: 10.2196/jmir.8480] [Medline: 29643048]

25. Provoost S, Lau HM, Ruwaard J, Riper H. Embodied conversational agents in clinical psychology: a scoping review. J Med Internet Res 2017 May 09;19(5):e151 [FREE Full text] [doi: 10.2196/jmir.6553] [Medline: 28487267]

26. Kidd C, Breazeal C. Robots at home: understanding long-term human-robot interaction. 2008 Presented at: IEEE/RSJ International Conference on Intelligent Robots and Systems; 2008; Nice. [doi: 10.1109/iros.2008.4651113]

27. Feil-Seifer D, Mataric M. Defining socially assistive robotics. 2005 Presented at: 9th International Conference on Rehabilitation Robotics; 2005; Chicago p. 465-468.

28. Mollahosseini A, Abdollahi H, Sweeny TD, Cole R, Mahoor MH. Role of embodiment and presence in human perception of robots' facial cues. Int J Hum Comput Stud 2018 Aug;116(116):25-39 [FREE Full text] [doi: 10.1016/j.ijhcs.2018.04.005]

29. Causo A, Vo G, Chen I, Yeo S. Design of robots used as education companion and tutor. Robotics Mechatronics 2015:75-84. [doi: $10.1007 / 978-3-319-22368-1 \quad 8]$

30. Fasola J, Mataric M. A socially assistive robot exercise coach for the elderly. J Hum Robot Interact 2013;2(2):1. [doi: 10.5898/jhri.2.2.fasola]

31. Kyong IK, Freedman S, Mataric M, Cunningham M, Lopez B. A hands-off physical therapy assistance robot for cardiac patients. 2005 Presented at: 9th International Conference on Rehabilitation Robotics; 2005; Chicago. [doi: 10.1109/icorr.2005.1501114]

32. Smarr C, Prakash A, Beer JM, Mitzner TL, Kemp CC, Rogers WA. Older adults' preferences for and acceptance of robot assistance for everyday living tasks. Proc Hum Factors Ergon Soc 2012 Sep;56(1):153-157 [FREE Full text] [doi: 10.1177/1071181312561009] [Medline: 25284971]

33. Bemelmans R, Gelderblom GJ, Jonker P, de Witte L. Effectiveness of robot paro in intramural psychogeriatric care: a multicenter quasi-experimental study. J Am Med Dir Assoc 2015 Nov 01;16(11):946-950. [doi: 10.1016/j.jamda.2015.05.007] [Medline: 26115817]

34. Blanson Henkemans OA, Bierman B, Janssen J, Neerincx M, Looije R, van der Bosch H, et al. Using a robot to personalise health education for children with diabetes type 1: a pilot study. Patient Educ Couns 2013 Aug;92(2):174-181. [doi: 10.1016/j.pec.2013.04.012] [Medline: 23684366]

35. Costescu CA, Vanderborght B, David DO. The effects of robot-enhanced psychotherapy: a meta-analysis. Rev Gen Psychol 2014;18(2):127-136. [doi: 10.1037/gpr0000007]

36. Interactive robotic social mediators as companions. URL: http://www.iromec.org [accessed 2019-06-24]

37. Vanderborght B, Simut R, Saldien J, Pop C, Rusu AS, Pintea S, et al. Using the social robot probo as a social story telling agent for children with ASD. Interactive Stud 2012;13(3):348-372. [doi: 10.1075/is.13.3.02van] 
38. Rabbitt S, Kazdin AE, Scassellati B. Integrating socially assistive robotics into mental healthcare interventions: applications and recommendations for expanded use. Clin Psychol Rev 2015 Feb;35:35-46. [doi: 10.1016/j.cpr.2014.07.001] [Medline: 25462112]

39. Scassellati B, Admoni H, Matarić M. Robots for use in autism research. Annu Rev Biomed Eng 2012 Aug;14:275-294. [doi: 10.1146/annurev-bioeng-071811-150036] [Medline: 22577778]

40. Kim ES, Berkovits LD, Bernier EP, Leyzberg D, Shic F, Paul R, et al. Social robots as embedded reinforcers of social behavior in children with autism. J Autism Dev Disord 2012 Oct 31;43(5):1038-1049. [doi: 10.1007/s10803-012-1645-2]

41. Bemelmans R, Gelderblom GJ, Jonker P, de Witte L. Effectiveness of robot Paro in intramural psychogeriatric care: a multicenter quasi-experimental study. J Am Med Dir Assoc 2015 Nov 01;16(11):946-950. [doi: 10.1016/j.jamda.2015.05.007] [Medline: 26115817]

42. Galvão Gomes da Silva J, Kavanagh DJ, Belpaeme T, Taylor L, Beeson K, Andrade J. Experiences of a motivational interview delivered by a robot: qualitative study. J Med Internet Res 2018 May 03;20(5):e116. [doi: 10.2196/jmir.7737]

43. Kurashige K, Tsuruta S, Sakurai E, Sakurai Y, Knauf R, Damiani E. Design of counseling robot for production by 3D printer. 2017 Presented at: 13th International Conference on Signal-Image Technology \& Internet-Based Systems (SITIS); 2017; Jaipur. [doi: 10.1109/sitis.2017.20]

44. Lane GW, Noronha D, Rivera A, Craig K, Yee C, Mills B, et al. Effectiveness of a social robot, "Paro," in a VA long-term care setting. Psychol Serv 2016 Aug;13(3):292-299. [doi: 10.1037/ser0000080]

45. Loi SM, Bennett A, Pearce M, Nguyen K, Lautenschlager NT, Khosla R, et al. A pilot study exploring staff acceptability of a socially assistive robot in a residential care facility that accommodates people under 65 years old. Int Psychogeriatr 2017 Dec 04;30(7):1075-1080. [doi: 10.1017/s1041610217002617]

46. Moyle W, Bramble M, Jones C, Murfield J. Care staff perceptions of a social robot called Paro and a look-alike Plush Toy: a descriptive qualitative approach. Aging Ment Health 2016 Dec 14;22(3):330-335. [doi: 10.1080/13607863.2016.1262820]

47. Šabanović S, Bennett C, Chang W, Huber L. PARO robot affects diverse interaction modalities in group sensory therapy for older adults with dementia. IEEE Int Conf Rehabil Robot 2013 Jun;2013:6650427. [doi: 10.1109/ICORR.2013.6650427] [Medline: 24187245]

48. Sefidgar YS, MacLean KE, Yohanan S, Van der Loos HM, Croft EA, Garland EJ. Design and evaluation of a touch-centered calming interaction with a social robot. IEEE Trans Affective Comput 2016 Apr 1;7(2):108-121. [doi: $10.1109 /$ taffc. 2015.2457893]

49. Valentí Soler M, Agüera-Ortiz L, Olazarán Rodríguez J, Mendoza Rebolledo C, Pérez Muñoz A, Rodríguez Pérez I, et al. Social robots in advanced dementia. Front Aging Neurosci 2015 Sep 03;7:1. [doi: 10.3389/fnagi.2015.00133]

50. Wada K, Ikeda Y, Inoue K, Uehara R. "Development and preliminary evaluation of a caregiver's manual for robot therapy using the therapeutic seal robot Paro". 1 Presented at: 19th International Symposium in Robot and Human Interactive Communication; 2010; Vaireggio p. 533-538. [doi: 10.1109/ROMAN.2010.5598615]

51. Wada K, Kouzuki Y, Inoue K. Field test of caregiver's manual for robot therapy using therapeutic seal robot. Alzheimer Dementia 2012 Jul;7(4):S636-S637. [doi: 10.1016/j.jalz.2011.05.1821]

52. Wada K, Takasawa Y, Shibata T. Robot therapy at facilities for the elderly in Kanagawa prefecture: a report on the experimental result of the first month. 2014 Presented at: The 23rd IEEE International Symposium on Robot and Human Interactive Communication; 2014; Edinburgh. [doi: 10.1109/roman.2014.6926252]

\section{Abbreviations}

COOP/WONCA: Primary Care Cooperative Information Project/World Organization of Colleges, Academies, and Academic Associations of General Practitioners/Family Physicians

CRECA: Contextual Respectful Counseling Agent

IPPA: Individually Prioritized Problems Assessment

QUALID: Quality of Life in Late Stage Dementia

RCT: randomized controlled trial

SAM: Self-Assessment Manikin

SAR: socially assistive robot

STAI-6: State-Trait Anxiety Inventory

VA: US Department of Veterans Affairs 
Edited by C Eichenberg; submitted 11.01.19; peer-reviewed by R Kok, E Hermes, C Pasarelu; comments to author 05.02.19; revised version received 01.04.19; accepted 03.06.19; published 24.07.19

Please cite as:

Scoglio AAJ, Reilly ED, Gorman JA, Drebing CE

Use of Social Robots in Mental Health and Well-Being Research: Systematic Review

J Med Internet Res 2019;21(7):e13322

URL: http://www.jmir.org/2019/7/e13322/

doi: $10.2196 / 13322$

PMID: $\underline{31342908}$

(C)Arielle AJ Scoglio, Erin D Reilly, Jay A Gorman, Charles E Drebing. Originally published in the Journal of Medical Internet Research (http://www.jmir.org), 24.07.2019. This is an open-access article distributed under the terms of the Creative Commons Attribution License (https://creativecommons.org/licenses/by/4.0/), which permits unrestricted use, distribution, and reproduction in any medium, provided the original work, first published in the Journal of Medical Internet Research, is properly cited. The complete bibliographic information, a link to the original publication on http://www.jmir.org/, as well as this copyright and license information must be included. 